\title{
NEUROLOGICAL INJURY IN THORACOLUMBAR BURST FRACTURES
}

\author{
D. LIMB, D. L. SHAW, R. A. DICKSON
}

From St James's University Hospital, Leeds, England

\begin{abstract}
Many authors recommend surgery to remove retropulsed bone fragments from the canal in burst fractures to 'decompress' the spinal canal. We believe, however, that neurological damage occurs at the moment of injury when the anatomy is most distorted, and is not due to impingement in the resting positions observed afterwards.

We studied 20 consecutive patients admitted to our spinal injuries unit over a two-year period with a T12 or L1 burst fracture. There was no correlation between bony or canal disruption and the degree of neurological compromise sustained but there was a significant correlation between the energy of the injury (as gauged by the Injury Severity Score) and the neurological status $(p<0.001)$. This suggests that neurological injury occurs at the time of trauma rather than being a result of pressure from fragments in the canal afterwards and questions the need to operate simply to remove these fragments.
\end{abstract}

J Bone Joint Surg [Br] 1995;77-B:774-7.

Received 24 May 1994; Accepted after revision 21 February 1995

The indications for the operative treatment of thoracolumbar burst fractures remain controversial, particularly as to the management of bone fragments within the spinal canal. There has been increasing support for an aggressive approach to their removal. This was suggested initially in the presence of partial neurological lesions (McEvoy and Bradford 1985), but such bone is now often routinely removed via a posterior (Larson et al 1976; Aebi et al 1987; Wood and Hanley 1992) or anterior (McAfee, Yuan and Lasda 1982; Johnson, Leatherman and Holt 1983; Kaneda, Abumi and Fujiya 1984; Kostuik 1988) approach even when there is no neurological deficit or biomechanical

D. Limb, BSc, FRCS Ed(Orth), Senior Registrar

D. L. Shaw, MSc, FRCS, Senior Registrar

R. A. Dickson, MA, ChM, FRCS, DSc, Professor

Academic Unit of Orthopaedic Surgery, Clinical Sciences Building, St James's University Hospital, Beckett Street, Leeds LS9 7TF, UK.

Correspondence should be sent to Mr D. Limb.

(C)1995 British Editorial Society of Bone and Joint Surgery 0301-620X/95/51049\$2.00

774 instability.

There is debate as to what degree of compromise of the canal should be accepted as the threshold for decompression. Most studies show little correlation between the degree of narrowing of the canal and the neurological injury sustained (Holdsworth 1963; Denis 1983; Gertzbein et al 1988; Herndon and Galloway 1988). There is a similarly poor relationship between the decompression achieved and the neurological recovery ensuing (Shuman et al 1985; Esses, Botsford and Kostuik 1990; Starr and Hanley 1992) except in cases of dramatic canal impingement (Kilcoyne et al 1983; Trafton and Boyd 1984), although, in general, unselected groups do slightly better after a formal decompression.

The static image of the canal obtained by CT at hours or days after the injury does not reflect the displacement at the time of injury which has determined the initial neurological insult. We believe that the neurological injury sustained is related to the energy dissipated at the time of injury. If true, this would explain the weak correlation of narrowing of the canal with neurological injury, as the degree of bony disruption would be related to this energy dissipation. We therefore investigated this hypothesis in a series of patients with thoracolumbar burst fractures treated at the Yorkshire Spinal Injuries Unit.

\section{PATIENTS AND METHODS}

We identified from the admissions register all patients admitted with a diagnosis of thoracolumbar fracture between January 1991 and December 1992. The radiographs were then reviewed to select those with a burst fracture affecting the T12 or L1 segment according to the criteria of Denis (1983). Patients with spinal injuries at multiple levels or pre-existing neurological deficits were excluded. Twenty patients fulfilled these criteria and the notes and radiographs were available for all. There were 13 men and 7 women of mean age 27 years (16 to 52). The mechanism of injury had been a road-traffic accident in five, a fall in 13 and a blow from a falling object in two.

Measurements were taken with a metric ruler from the plain AP and lateral films and lateral tomograms, rather than the CT scans, of the retropulsion of the posterior-body fragment, the interpedicular distance and the anterior- and posterior-body heights both at the level of fracture and at the levels above and below. 


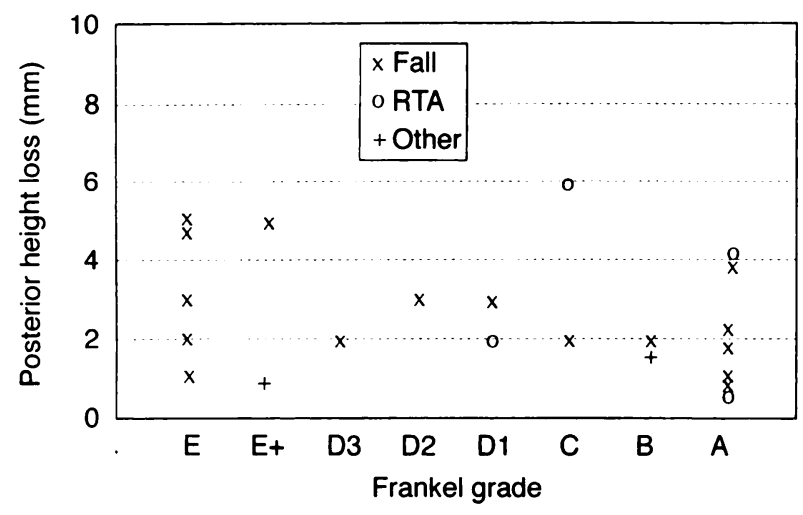

Fig. 1

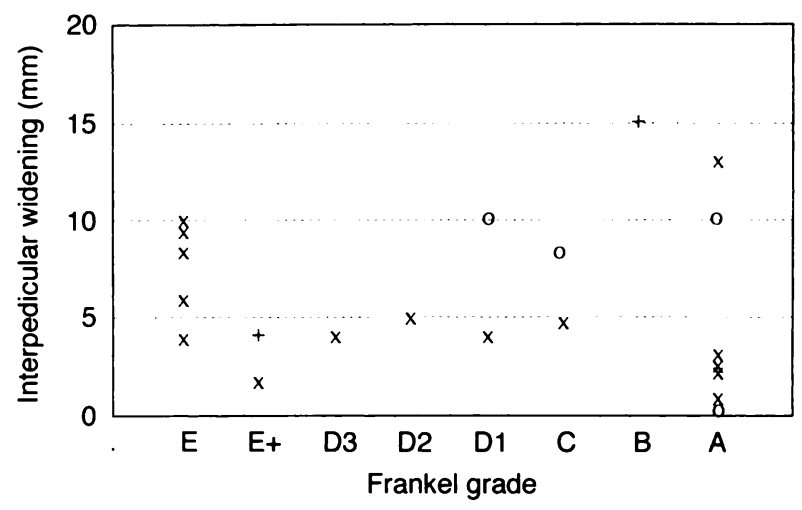

Fig. 3

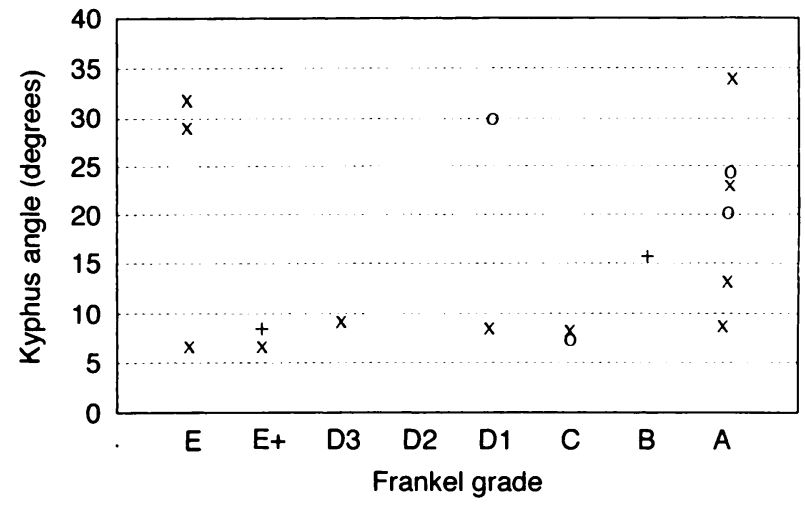

Fig. 2

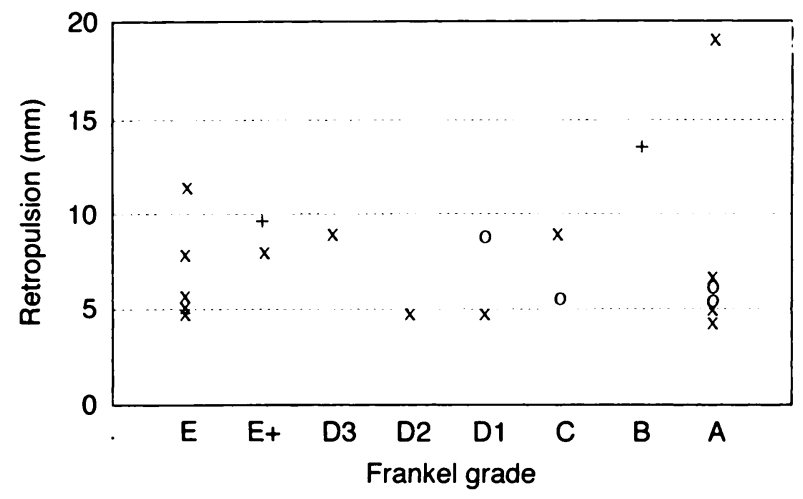

Fig. 4

Scatter diagrams showing the results of four radiological measurements related to the neurological deficit on admission.

From the uninjured levels, an estimate of the dimensions at the level of injury before damage could be made and the changes resulting from the accident could be assessed. This estimate was taken as the average of the corresponding measurement taken at the level above and the level below; for interpedicular distance this method has been shown to be accurate even at the thoracolumbar junction (Hinck, Clark and Hopkins 1966).

The notes of all the patients were then reviewed and the mechanism of injury and the resulting initial neurological deficit according to the Frankel grade (as modified by Bradford and McBride 1987) were recorded. Patients with transient neurological symptoms or signs which had resolved before admission to the spinal injuries unit were assigned to grade E+. A numerical score was then allocated to each Frankel grade to allow statistical analysis, with a score of 1 being assigned to grade E, 2 to E+, 3 to Dl and so on, until grade $A$ which received a score of 8 . The spinal injury and associated injuries were assigned an abbreviated injury score and from these, an Injury Severity Score (ISS) was calculated for each patient. The element of this to which neurological injury contributed was noted for each case.

The anatomical and energy-dependent parameters were then plotted against the neurological deficit, and Pearson's correlation coefficient calculated for each pair to determine the relationship of each variable to the degree of cord injury sustained.

\section{RESULTS}

The loss of posterior-body height, the kyphus angle, interpedicular widening and the degree of retropulsion of fragments into the canal were compared with the neurological deficit (Figs 1 to 4 ).

We found no statistically significant correlation between any of the results for the degree of disruption of the bony anatomy, including retropulsion of bony fragments into the canal and the neurological deficit as recorded on admission to hospital (Table I). There was, however, a strongly pos-

Table I. The correlation between factors studied and the degree of neurological compromise as measured by the Frankel grade on admission

\begin{tabular}{lcl}
\hline Factor & Correlation coefficient $(\mathbf{r})$ & Significance \\
\hline Anterior height loss & 0.20 & NS* \\
Posterior height loss & -0.30 & NS \\
Interpedicular widening & 0.24 & $\mathrm{NS}$ \\
Kyphus angle & 0.07 & $\mathrm{NS}$ \\
Intracanal retropulsion & 0.12 & $\mathrm{NS}$ \\
Injury Severity Score & 0.91 & $\mathrm{p}<0.01$ \\
\hline
\end{tabular}

* not significant 


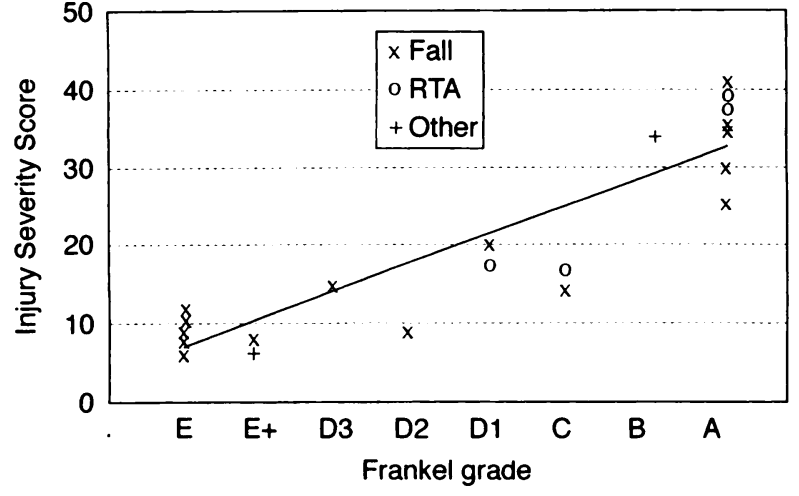

Fig. 5

Scatter diagram showing the relation between the Injury Severity Score and the neurological deficit on admission.

itive correlation $(r=0.91, p<0.01)$ between the ISS and the Frankel grade (Fig. 5), which remained even after subtraction of the score for the spinal injury from the calculation.

This suggests that the neurological injury does not have a cause-and-effect relationship with the degree of bursting of the vertebra, but is dependent on those factors which produce a high ISS.

\section{DISCUSSION}

There remains no clear consensus as to the best treatment for thoracolumbar burst fractures. Conservative treatment has yielded acceptable results by which newer operative measures can be gauged (Holdsworth 1963; Bedbrook 1975; Davies, Morris and Hill 1980; Weinstein, Collalto and Lehmann 1988; Mumford et al 1993). There are now numerous series which have shown that the best surgical results are better than those achieved by sound conservative care (Kaneda et al 1984; Bradford and McBride 1987; Kostuik 1988). High complication rates have been encountered, however, although the use of fixation systems has given improved results (Cotler, Vernace and Michalski 1986; Wilmot and Hall 1986; Been 1991; Daniaux et al 1991).

The management of the patient with neurological injury is even less certain. Excellent clearance of the spinal canal can be achieved by operation through both posterior and anterior approaches. Even if surgery is not undertaken, however, the retropulsed fragments will remodel (Johnsson et al 1991; Cantor et al 1993), resulting in the gradual formation of a canal as adequate as that achieved by some surgical approaches.

Some prospective studies have suggested that the neurological improvement obtained by such 'decompressive' surgery is better than that which is known to occur spontaneously. Unfortunately, these are not controlled studies, and include patients with different anatomical levels and degrees of injury, with some being operated on while still in spinal shock and others several weeks after injury. Indications for operation also included patients who were deteriorating neurologically as well as those with stable neurological signs but with identified retropulsed fragments. Neurological deterioration is seen as an indication for urgent operation even among the more conservatively inclined, and such patients should probably be excluded from trials which assess the effectiveness of canal clearance in facilitating nervous recovery. Other studies have shown that late decompression weeks or months after injury can yield considerable improvement (McAfee et al 1982).

We have investigated the relationship of the fracture pattern, including canal compromise, to the neurological injury. We used plain films and tomograms rather than CT. The Yorkshire Spinal Injuries Unit acts as a secondary referral centre for the Yorkshire region and even when CT scans were available, they did not conform to a standard protocol, having been taken at different times after the injury and on different machines. CT is widely accepted as the investigation of choice in these injuries since it delineates the anatomy of the fracture and helps in preoperative planning. It may pose problems, however, when used for studies which compare measurements in different patients. For instance, the degree of bony retropulsion measured depends on the precise gantry angle in relation to the vertebral plane, and also the slice thickness, which may miss the apex of angulated fragments. Loss of posteriorand anterior-body height and the kyphus angle can be measured only after multiplanar reconstruction, assuming enough levels are all scanned in the same plane, and even then current scanners have only a resolution of 0.7 line pairs $/ \mathrm{mm}$ (or less) compared with at least 4 line pairs $/ \mathrm{mm}$ for plain films.

The posterior vertebral line is a reliable indicator of retropulsion and represents the posteriorly-displaced fragments seen on CT (Daffner, Deeb and Rothfus 1987), although absolute values measured by the two techniques on the same specimens do differ (Keene 1984). The same technique was used for all films, however, and this should not influence the relationships being investigated in this study.

By using the height of fall or speed of a vehicular crash and the body mass of the patient, a crude estimate of changes in kinetic and potential energy undergone during injury can be made. While this is open to error, we found that the resulting calculated energy of injury correlated strongly with the ISS and with neurological injury in these patients.

The results of our study support the view that damage to the cord occurs at the time of the accident and strongly correlates with the energy of the injury. Bone fragments within the canal which are seen on imaging after the accident do not usually represent a continuing compressive force. Their position is almost certainly less displaced than at the time of the injury when the actual cord damage occurred, the cord failing under tension as it was stretched 
and angulated over the displaced fragments. The degree of residual displacement may correlate weakly with the neurological injury because fragment displacement is also related to the energy of the injury-inducing forces. Thus, there may be little to be gained in operating simply to remove the fragment if the patient is not deteriorating neurologically.

Animal experiments have shown that cord compression does have a penumbra region which can be allowed to recover by release of the compression. Studies in rats, however, could not produce complete paraplegia even by prolonged compression (Dolan, Tator and Endrenyi 1980), and in monkeys pathological changes in the cord were relentless, despite the clinical recovery of the animals (Ducker, Kindt and Kempf 1971). There is no evidence that this effect occurs in the clinical situation other than in a progressing neurological lesion which can be detected clinically and dealt with by early adequate decompression directed by preoperative imaging.

We consider that a thoracolumbar burst fracture in a patient who is neurologically stable, with or without a partial lesion of the cord, does not require formal decompression on the basis of any arbitrary degree of canal compromise. If surgical treatment is indicated for other reasons, it should be addressed to these and not to clearing the canal. Persistent symptoms due to a root-canal or central spinal stenosis after the fracture can be dealt with as necessary on a symptomatic basis.

No benefits in any form have been received or will be received from a commercial party related directly or indirectly to the subject of this article.

\section{REFERENCES}

Aebi M, Etter C, Kehl T, Thalgott J. Stabilization of the lower thoracic and lumbar spine with the internal spinal skeletal fixation system. Spine 1987;12:544-51.

Bedbrook GM. Treatment of thoracolumbar dislocation and fractures with paraplegia. Clin Orthop 1975;112:27-43.

Been HD. Anterior decompression and stabilisation of thoracolumbar burst fractures by the use of the Slot-Zielke device. Spine 1991;16:70-7.

Bradford DS, McBride GG. Surgical management of thoracolumbar spine fractures with incomplete neurologic deficits. Clin Orthop 1987;218:201-16.

Cantor JB, Lebwohl NH, Garvey T, Eismont FJ. Nonoperative management of stable thoracolumbar burst fractures with early ambulation and bracing. Spine 1993;8:971-6.

Cotler JM, Vernace JV, Michalski JA. The use of Harrington rods in thoracolumbar fractures. Orthop Clin North Am 1986;17:87-103.

Daffner RH, Deeb ZL, Rothfus WE. The posterior vertebral body line: importance in the detection of burst fractures. AJR 1987;148:93-6.

Daniaux H, Seykora P, Genelin A, Lang T, Kathrein A. Application of posterior plating and modifications in thoracolumbar spine injuries: indications, techniques and results. Spine 1991;16 Supp:125-33.
Davies WE, Morris JH, Hill V. An analysis of conservative (non-surgical) management of thoracolumbar fractures and fracture dislocations with neural damage. J Bone Joint Surg [Am] 1980:62-A:1324-8.

Denis $\mathbf{F}$. The three column spine and its significance in the classification of acute thoracolumbar spinal injuries. Spine 1983;8:817-31

Dolan EJ, Tator CH, Endrenyi L. The value of decompression for acute experimental spinal cord compression injury. J Neurosurg 1980; 53:749-55.

Ducker TB, Kindt GW, Kempf LG. Pathological findings in acute experimental spinal cord trauma. J Neurosurg 1971;35:700)-8.

Esses SI, Botsford DJ, Kostuik JP. Evaluation of surgical treatment for burst fractures. Spine 1990;15:667-73.

Gertzbein SD, Court-Brown CM, Marks P, et al. The neurological outcome following surgery for spinal fractures. Spine 1988;13:641-4.

Herndon WA, Galloway D. Neurologic return versus cross-sectional canal area in incomplete thoracolumbar spinal cord injuries. J Trauma 1988;28:680-3.

Hinck VC, Clark WM, Jr, Hopkins CE. Normal interpediculate distances (minimum and maximum) in children and adults. Amer $J$ Roentgen 1966;97:141-53.

Holdsworth FW. Fractures, dislocations and fracture-dislocations of the spine. J Bone Joint Surg [Br] 1963;45-B:6-20.

Johnson JR, Leatherman KD, Holt RT. Anterior decompression of the spinal cord for neurological deficit. Spine 1983:8:396-405.

Johnsson R, Herrlin K, Hagglund G, Stromqvist B. Spinal canal remodeling after thoracolumbar fractures with intraspinal bone fragments. Acta Orthop Scand 1991;62:125-7.

Kaneda K, Abumi K, Fujiya M. Burst fractures with neurologic deficits of the thoracolumbar-lumbar spine: results of anterior decompression and stabilization with anterior instrumentation. Spine 1984;9:788-95.

Keene JS. Radiographic evaluation of thoracolumbar fractures. Clin Orthop 1984:189:58-64.

Kilcoyne RF, Mack LA, King HA, Ratcliffe SS, Loop JW. Thoracolumbar spine injuries associated with vertical plunges: reappraisal with computed tomography. Radiology 1983;146:147-40.

Kostuik JP. Anterior fixation for burst fractures of the thoracic and lumbar spine with or without neurological involvement. Spine 1988;13:286-93.

Larson SJ, Holst RA, Hemmy DC, Sances A Jr. Lateral extracavitary approach to traumatic lesions of the thoracic and lumbar spine. $J$ Neurosurg 1976;45:628-37.

McAfee PC, Yuan HA, Lasda NA. The unstable burst fracture. Spine 1982;7:365-73.

McEvoy RD, Bradford DS. The management of burst fractures of the thoracic and lumbar spine: experience in 53 patients. Spine 1985;10: $631-7$.

Mumford J, Weinstein JN, Spratt KF, Goel VK. Thoracolumbar burst fractures: the clinical efficacy and outcome of nonoperative management. Spine 1993;18:955-70.

Shuman WP, Rogers JV, Sickler ME, et al. Thoracolumbar burst fractures: CT dimensions of the spinal canal relative to post surgical improvement. AJR 1985;145:337-41.

Starr JK, Hanley EN. Junctional burst fractures. Spine 1992:17:551-7.

Trafton PG, Boyd CA, Jr. Computed tomography of thoracic and lumbar spine injuries. J Trauma 1984:24:506-15.

Weinstein JN, Collalto P, Lehmann TR. Thoracolumbar "burst" fractures treated conservatively: a long term follow-up. Spine 1988; 13:33-8.

Wilmot CB, Hall KM. Evaluation of acute surgical intervention in traumatic paraplegia. Paraplegia 1986;24:71-6.

Wood EG III, Hanley EN Jr. Thoracolumbar fractures: an overview with emphasis on the burst injury. Orthopedics 1992;15:319-23. 